\title{
Market Analysis and Problem Faced by the Wild Pomegranate Growers in Himachal Pradesh, India
}

\author{
Devender Singh Dogra, Chandresh Guleria*, Amit Guleria and Manoj Kumar Vaidya \\ Department of Social Sciences, Dr Yashwant Singh Parmar University of Horticulture and \\ Forestry, Nauni, Solan- 173230 (H.P.), India \\ *Corresponding author
}

\section{A B S T R A C T}

\section{Keywords \\ Marketing cost, Marketing efficiency, Price spread, Wild pomegranate and Chi-square. \\ Article Info \\ Accepted: 19 June 2017 Available Online: 10 July 2017}

Wild pomegranate is one of the important cash crop tree species of the mid-hill zone of western Himalayan region. A multistage random sampling technique was used for the selection of the respondents. The analysis was based on data based on survey of 50 farm households. Highest efficiency of channel-A was observed (271.73) but the volume transacted was very less $(5 \%)$ and high quality produce was traded through this channel. Total marketing cost varies from Rs. 55.00 to Rs. 1618.00 and marketing margin Rs. 0.00 to Rs. 4382 in different marketing channels, Price spread were examined Rs. 55 in channel A to Rs. 6000 in channel E. Producer's share in consumer's rupee were examined in different marketing channels which varied from $99.63 \%$ to $70.00 \%$ in channel A to channel B, implying channel-A most efficient. The $\chi^{2}$ value was found non-significant for the problems like lack of storage facilities and delayed payments indicating these problems equally same for different farm size categories. Information on market potential, price and market intelligence is required to be collected through regular market survey so that proper marketing strategy could be formulated. A sound data base of production potential along with their potential needs to be created.

\section{Introduction}

Wild pomegranate (Punica granatum L.) is a wild fruit of family Punicaceae which resembles with cultivated pomegranate for various morphological characters (Sharma and Sharma, 1990). Wild pomegranate is one of the important cash crop tree species of the mid-hill zone of western Himalayan region. It is distributed in Solan, Sirmaur, Mandi, Kullu, Shimla and Chamba districts of Himachal Pradesh (Bhrot, 1998). It is a good species for afforestation of degraded hill slopes or rehabilitation of wastelands. Its economic importance in the region has good potential of becoming a good source of generating income. The adoption of improved technologies in production and efficient marketing system is a pre-requisite for stable and remunerative prices to the producers which go in a long way to provide necessary incentives to increase production and income of the growers. With the improvement in the technology of drying and new market avenues, the quality and the efficiency in drying of wild pomegranate has increased manifold, but the profitability has not shown that much significance in the improvement of rural household engaged in the dried pomegranate business (Dogra, 2013). This 
may be due to the lack of awareness and authentic data on cost of production and selection of right marketing channels.

\section{Materials and Methods}

\section{Sampling Design}

A multistage random sampling technique was used for the selection of the respondents. The main objective of the study was to examine marketing aspects of wild pomegranate and attempts to describe the various facets of wild pomegranate farming in the study area.

\section{Location of study area}

The mid hill zone, ranging in altitude from 800 to 1600 meters, of Himachal Pradesh has a comparative advantage of growing wild pomegranate due to congenial climatic conditions for its growth.

\section{Selection of sample size}

Pachad block of district Sirmour having the maximum production of wild pomegranate among six blocks was selected for the study. In the first stage, a complete list of villages having major wild pomegranate area was prepared with the help of Agricultural Development Office and Tehsil Office of selected block. From this list, a nucleus village was selected having maximum concentration of wild pomegranate farmers. In the second stage, a cluster of three villages was formed by including adjoining villages. Thus, it forms a belt of wild pomegranate farmers including villages Darodaevriya, Narag, Nohra and Naalti. In the third stage of sampling, a complete list of wild pomegranate farmers from the selected villages was prepared with the help of Panchayat officials. From this list ten farmers from each village were selected randomly, thus forming a sample of 40 farmers from the study area.

To examine the various marketing aspects of anardana, five local traders and five wholesalers were selected randomly from the local market of Solan. Five wholesalers and five retailers from the Shimla market were selected to study the functioning of market in Himachal Pradesh. Five wholesalers were also randomly selected from the Amritsar market dealing with wild pomegranate.

\section{Data analysis}

Analysis of data was done by using SPSS2012 and XLSTAT-2015 through descriptive statistics such as chi square test, marketing margin, marketing cost, price spread, marketing efficiency and producer's share in consumer's rupees respectively.

\section{For the marketing margin}

Marketing Margin $(\mathrm{MM})=$ Selling Price $(\mathrm{SP})$ - Purchase price (PP)

\section{Marketing efficiency of the marketing channels}

In case of marketing channels, the marketing efficiency is concerned with the movement of goods from producer to consumer at the lowest possible cost consistent with the provision of services desired by the consumers. The marketing efficiency of various channels in the study area has been computed byusing Acharya's method (Acharya and Agarwal, 2011), as under:

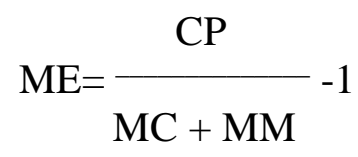


Where,

$\mathrm{ME}=$ Marketing efficiency

$\mathrm{CP}=$ Consumer's price

$\mathrm{MC}=$ Total marketing costs.

$\mathrm{MM}=$ Total marketing margins

This study was restricted to only farmer who deal on local apple in the state.

The study was based on the data collected for one year only (2012-13) which may not necessarily hold true for other periods as well.

\section{Producer's share in consumer's rupee}

It is the price received by the farmer expressed by the farmer expressed as a percentage of retail price (i.e. the price paid by the consumer) (Acharya and Agarwal, 2011). If $P_{r}$ is the retail price, the producer's share in consumer's rupee $\left(\mathrm{P}_{\mathrm{s}}\right)$ may be expressed as follow:

Ps $=\frac{P_{f}}{P_{r}} \times 100$

Where,

$\mathrm{P}_{\mathrm{s}}$ : Producer's share in consumer's rupee

$\mathrm{P}_{\mathrm{r}}$ : Retail price or price paid by consumer

$\mathrm{P}_{\mathrm{f}}$ : Farmer's price

\section{Chi-square}

The chi-square test is one of the simplest and most widely used non-parametric tests in statistical work. The quantity $\chi^{2}$ describes the magnitude of the discrepancy between theory and observation (Gupta, 2009). It is defined as:

$x^{2}=\sum \frac{(\mathrm{O}-\mathrm{E})^{2}}{\mathrm{E}}$

Where $\mathrm{O}$ refers to the observed frequencies and $\mathrm{E}$ refers to the expected frequencies.

\section{Results and Discussion}

\section{Marketing channels}

The marketing channel means the route through which a commodity travels from producer to the final consumer. Due to the existence of various agencies working between producer and consumer, there are different marketing channels for the same commodity. The agencies involved in the marketing of anardana and its by-product in the study area are local traders, primary wholesalers, secondary wholesalers and retailers. Findings were in line with the results of Randev (2005), who studied marketing channels of apple in Himachal Pradesh. Table 1 shows different marketing channel so fanardana in Himachal Pradesh.

\section{Sale through local traders}

This agency was most commonly used in Channels- C, D and E. Local traders collected the produce from the doorsteps of the producers and further sold it to primary wholesaler or secondary wholesaler when collected in sufficient amount. In the study area, about 85.24 per cent of the produce was disposed of through these channels (Table 2).

\section{Sale through retailer}

Four farmers adopted this agency for the sale of anardana. The total quantity marketed through this channel worked out to be 9.26 per cent of the total produce sold in the study area. Generally, the small and medium farmers sold the anardana directly to the retailers in market to fetch good prices.

\section{Direct sale to consumer}

This channel establishes a direct relationship with the consumer. This channel promises higher share of producer in the consumer's 
rupee. About 5 per cent of the total produce was marketed through this channel. The medium farmers sold about 14.29 per cent of their produce, whereas proportion in large category was 11.11 per cent.

It can further be observed from the results (Table 2 and Fig. 1) that Channel- $\mathrm{C}$ was found to be the most preferred channel, since 47.50 per cent of the produce was traded. The major contribution were by marginal farmers (60 \%) followed by medium farmers (57.14 $\%)$ and large farmers $(44.44 \%)$.

\section{Price spread}

In the marketing of agricultural commodities, the difference between the price paid by the consumer and the price received by the producer for an equivalent quantity of farm produce is known as price spread or gross marketing margin. It includes marketing cost (the cost involved in moving the product from the point of production to point of consumption i.e. the cost of performing the various marketing functions and of the various agencies) and marketing margin (profits of the various market functionaries involve in moving the produce from point of production to ultimate consumer).A cursory glance at table 3 revealed that, in absolute terms, anardana producers received highest net returns in Channel- A. Net margins of local traders turned out to be Rs. 1720 in Channel- $C$ and Channel-D. The primary wholesaler's net margins were computed Rs. 1832 in Channel-E and its respective marketing expenses were Rs. 1138. Net margin of secondary wholesaler ranged from Rs. 888 per cent in Channel- C to Rs. 980in Channel- D. Retailer's net margin was higher in Channel- B (Rs. 862) followed by Channel$\mathrm{D}$ and Channel-C.

Table.1 Marketing channels of anardana

\begin{tabular}{|l|l|}
\hline \multicolumn{1}{|c|}{ Marketing Channels } & \multicolumn{1}{c|}{ Marketing intermediaries } \\
\hline Channel- A & Producer - Consumer \\
\hline Channel- B & Producer - Retailer - Consumer \\
\hline Channel- C & Producer - Local Trader - Secondary wholesaler - Consumer (Industries) \\
\hline Channel- D & Producer - Local Trader - Secondary wholesaler - Retailer - Consumer \\
\hline Channel- E & $\begin{array}{l}\text { Producer - Local Trader - Primary wholesaler - Secondary wholesaler - Retailer - } \\
\text { Consumer }\end{array}$ \\
\hline
\end{tabular}

Table.2 Quantity of anardana marketed through various channels (Per cent)

\begin{tabular}{|l|c|c|c|c|c|}
\hline \multicolumn{1}{|c|}{ Particulars } & Marginal & Small & Medium & Large & Overall \\
\hline Channel- A & 0.00 & 0.00 & 14.29 & 11.11 & 5.00 \\
\hline Channel- B & 0.00 & 14.29 & 12.49 & 9.22 & 9.26 \\
\hline Channel- C & 60.00 & 35.71 & 57.14 & 44.44 & 47.50 \\
\hline Channel- D & 30.00 & 28.57 & 16.08 & 22.22 & 25.31 \\
\hline Channel- E & 10.00 & 21.43 & 0.00 & 13.00 & 12.93 \\
\hline & $\mathbf{1 0 0 . 0 0}$ & $\mathbf{1 0 0 . 0 0}$ & $\mathbf{1 0 0 . 0 0}$ & $\mathbf{1 0 0 . 0 0}$ & $\mathbf{1 0 0 . 0 0}$ \\
\hline
\end{tabular}


Table.3 Price spread of anardana among the different marketing channels in the Shimla and Solan market of Himachal Pradesh (Rupees per Quintal)

\begin{tabular}{|c|c|c|c|c|c|}
\hline \multirow{2}{*}{ Marketing functionaries } & \multicolumn{5}{|c|}{ Marketing channels } \\
\hline & $\mathbf{A}$ & $\mathbf{B}$ & $\mathbf{C}$ & $\mathbf{D}$ & $\mathbf{E}$ \\
\hline \multicolumn{6}{|l|}{ Producer } \\
\hline Sale Price & 15000 & 15000 & 14000 & 14000 & 14000 \\
\hline Expenses & 55 & 65 & 0 & 0 & 0 \\
\hline Net Margin & 14945 & 14935 & 14000 & 14000 & 14000 \\
\hline \multicolumn{6}{|c|}{ Local Trader-Itinerant Merchant } \\
\hline Sale Price & & & 17000 & 17000 & 15000 \\
\hline Expenses & & & 1280 & 1280 & 220 \\
\hline Net Margin & & & 1720 & 1720 & 780 \\
\hline \multicolumn{6}{|l|}{ Primary Wholesaler } \\
\hline Sale Price & & & & & 18000 \\
\hline Expenses & & & & & 1138 \\
\hline Net Margin & & & & & 1862 \\
\hline \multicolumn{6}{|l|}{ Secondary Wholesaler } \\
\hline Sale Price & & & 18000 & 18000 & 19000 \\
\hline Expenses & & & 112 & 92 & 92 \\
\hline Net Margin & & & 888 & 908 & 908 \\
\hline \multicolumn{6}{|l|}{ Retailer } \\
\hline Sale Price & & 16000 & & 19000 & 20000 \\
\hline Expenses & & 138 & & 168 & 168 \\
\hline Net Margin & & 862 & & 832 & 832 \\
\hline Consumer Price & 15000 & 16000 & 18000 & 19000 & 20000 \\
\hline
\end{tabular}

Table.4 Marketing efficiency and producer's share in consumer's rupee

\begin{tabular}{|l|c|c|c|c|c|}
\hline \multirow{2}{*}{ Particulars } & \multicolumn{3}{|c|}{ Marketing Channel } & \\
\cline { 2 - 6 } & A & B & C & D & E \\
\hline Total marketing cost (Rs/qtl) & 55 & 203 & 1392 & 1540 & 1618 \\
\hline Consumer's price (Rs/qtl) & 15000 & 16000 & 18000 & 19000 & 20000 \\
\hline Producer's price & 14945 & 14935 & 14000 & 14000 & 14000 \\
\hline Total net marketing margin (Rs/qtl) & 0 & 862 & 2608 & 3460 & 4382 \\
\hline Marketing efficiency & 271.73 & 14.02 & 3.50 & 2.80 & 2.33 \\
\hline Price Spread (Rs/qtl) & 55 & 1065 & 4000 & 5000 & 6000 \\
\hline Producer's share in consumer's rupee (\%) & 99.63 & 93.34 & 77.78 & 73.68 & 70.00 \\
\hline
\end{tabular}


Table.5 Problems faced by the wild pomegranate farmers in the study area (Multiple Response per cent)

\begin{tabular}{|c|c|c|c|c|c|c|c|}
\hline Sr. No. & Problems Faced & Marginal & Small & Medium & Large & Overall & $\chi^{2}$ \\
\hline $\mathbf{1}$ & \multicolumn{7}{|l|}{ Production } \\
\hline i) & Lack of Capital & 70.00 & 50.00 & 42.86 & 33.33 & 50.00 & $14.79^{*}$ \\
\hline ii) & Lack of Quality Planting material & 80.00 & 64.29 & 85.71 & 44.44 & 67.50 & $14.94^{*}$ \\
\hline iii) & Lack of Technical Knowledge & 60.00 & 57.14 & 71.43 & 44.44 & 57.50 & 6.33 \\
\hline iv) & Lack of irrigation facilities & 90.00 & 71.43 & 71.43 & 66.67 & 75.00 & 4.27 \\
\hline v) & High wages of labour & 20.00 & 35.71 & 71.43 & 77.78 & 47.50 & $45.46^{*}$ \\
\hline 2 & \multicolumn{7}{|l|}{ Harvesting } \\
\hline i) & $\begin{array}{l}\text { Non-availability of labour at peak } \\
\text { of operation time }\end{array}$ & 12.62 & 42.86 & 65.71 & 68.89 & 47.52 & $42.66^{*}$ \\
\hline ii) & Difficulty in Harvesting the fruits & 90.00 & 64.29 & 71.43 & 55.56 & 70.00 & $9.14^{*}$ \\
\hline iii) & Large area to cover & 80.00 & 85.71 & 71.43 & 55.56 & 75.00 & 7.07 \\
\hline 3 & \multicolumn{7}{|l|}{ Marketing } \\
\hline i) & Lack of storage facilities & 60.00 & 57.14 & 57.14 & 44.44 & 55.00 & 2.66 \\
\hline ii) & Delayed payments & 60.00 & 42.86 & 42.86 & 44.44 & 47.50 & 4.39 \\
\hline 4 & \multicolumn{7}{|l|}{ Market intelligence } \\
\hline i) & Inadequate information & 60.00 & 50.00 & 57.14 & 44.44 & 52.50 & 2.80 \\
\hline ii) & Misleading information & 70.00 & 57.14 & 57.14 & 44.44 & 57.50 & 5.71 \\
\hline iii) & Late information & 80.00 & 64.29 & 57.14 & 44.44 & 62.50 & $10.74^{*}$ \\
\hline 5 & \multicolumn{7}{|l|}{ Others } \\
\hline i) & Birds/Animals Menace & 70.00 & 64.29 & 71.43 & 44.44 & 62.50 & 7.44 \\
\hline ii) & Fruit fly attack & 60.00 & 78.57 & 71.43 & 66.67 & 70.00 & 2.66 \\
\hline iii) & Parasite attack & 70.00 & 78.57 & 71.43 & 55.56 & 70.00 & 4.05 \\
\hline iv) & Pre-mature falling of fruits & 70.00 & 85.71 & 71.43 & 33.33 & 67.50 & $23.01^{*}$ \\
\hline v) & Drying of trees & 80.00 & 71.43 & 71.43 & 22.22 & 62.50 & $33.98^{*}$ \\
\hline vi) & Weather problem & 90.00 & 78.57 & 71.43 & 44.44 & 72.50 & $15.80^{*}$ \\
\hline
\end{tabular}

*significant at 5 per cent level of significance

Fig.1 Quantity transacted by different marketing channels

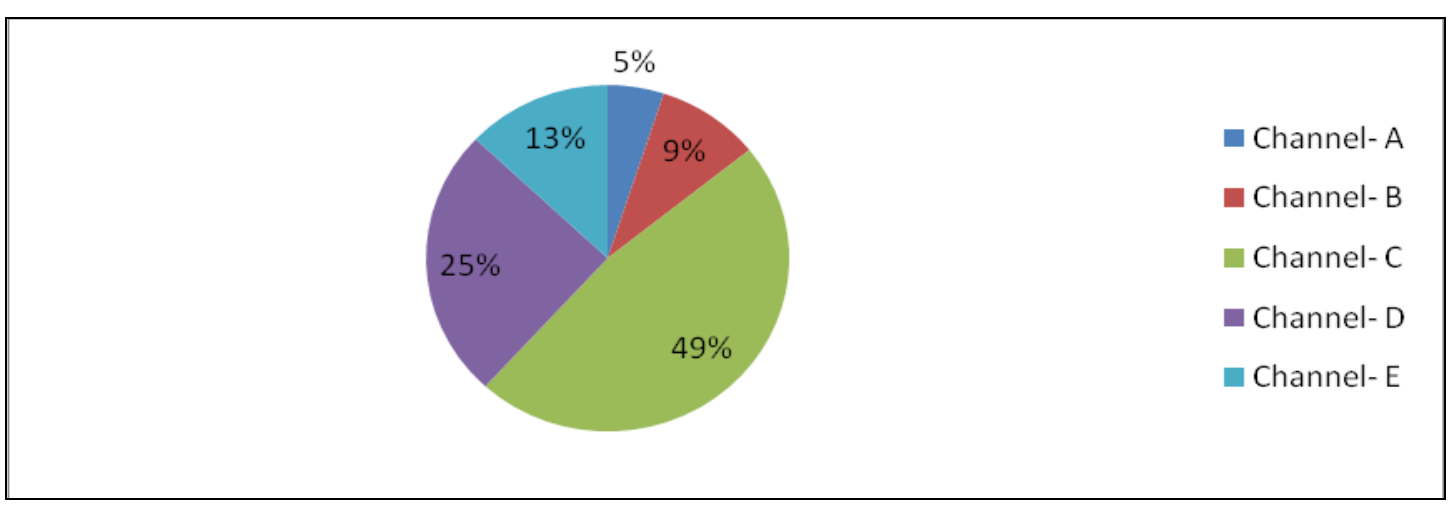

\section{Marketing efficiency}

Marketing efficiency is the effectiveness or competence with which a market structure performs its designated function (Jasdanwalla, 1966). Simply it is indicators of overall performance of the marketing channels have been presented in table 4 . The results indicate highest efficiency in channel A (271.73) followed by channels B (14.02), C (3.50), D (2.80) and $\mathrm{E}$ (2.33) respectively. Though channel A was found efficient but the volume 
transacted was very less (5\%) and high quality produce was traded through this channel. Findings were in line with the results of Kashyap and Guleria (2015), who studied marketing aspects of apple in Himachal Pradesh.

The analysis reveals the net price, on per quintal basis, received by the growers to be Rs.14945, Rs. 14945, Rs. 14000, Rs. 14000 and Rs. 14000 in channel A, B, C, D and E respectively. Consumer's price or retailer's selling price were varied Rs. 15000 to Rs. 20000. Total marketing cost varies from Rs. 55.00 to Rs. 1618.00 and marketing margin Rs. 0.00 to Rs. 4382 in different marketing channels, Price spread were examined Rs. 55 in channel A to Rs. 6000 in channel E. Producer's share in consumer's rupee were examined in different marketing channels which varies from $99.63 \%$ to $70.00 \%$ in channel A to channel B, implies channel A was more efficient.

\section{Problems in the production and marketing of anardana}

The problems faced by the farmers were classified broadly under production, harvesting and marketing related problems and the results have been presented in table 5 .

\section{Production related problems}

Based on the data in table 5 , it could be observed that all the farmers faced the major problem of lack of irrigation facilities in common $(75.00 \%)$ followed by lack of quality planting material $(67.50 \%)$ and lack of technical knowledge $(57.50 \%)$. The $\chi^{2}$ value was found significant for the problems like lack of capital, lack of quality planting material and high wages of labour which means these problems were significantly different with farm size categories.

\section{Harvesting related problems}

It was found that non availability of labour at peak of operation time was more among the large size farmers $(68.89 \%)$ as the harvesting time of wild pomegranate was coincided with the other seasonal vegetable crops farming. The $\chi^{2}$ value was found significant for the problems like nonavailability of labour and difficulty in harvesting the fruits at peak of operation time which means these problems were significantly different with farm size categories.

\section{Marketing related problems}

An informal discussion with the sampled farmers revealed that marketing of anardana has a few marketing problems. Mainly, the problem of anardana producers as a whole was lack of market information. The producers got the inadequate and misleading information about the market prices by the traders. The payments were also delayed by the traders to the producers. The $\chi^{2}$ value found non-significant for the problems like lack of storage facilities and delayed payments which mean these problems were similar for farm size categories. Further the $\chi^{2}$ value was found significant for the problems like late information, pre-mature falling of fruits, drying of trees and weather problem which means these problems were significantly different with farm size categories.

In conclusion, Wild pomegranate is an important non-timber forest product (NTFP) in mid hills of Western Himalayas. It is one of those fruits, which have got great economic importance in their respective region. Five marketing channels comprising of producers, local traders, primary wholesalers, secondary wholesalers, retailers and consumers were identified in anardana trade in the study area. 
It was observed that 47.50 per cent of total produce was traded to industries through Channel- C (Producer - Local Trader Secondary wholesaler - Consumer (Industries).Highest efficiency of channel-A was observed (271.73) but the volume transacted was very less (5\%) and high quality produce was traded through this channel. Lack of irrigation facilities was the major problem among farmer in the study area. Harvesting of wild pomegranate was a major problem due to thorny nature of plant and the larger area to cover. $\chi^{2}$ value was found non-significant for the problems like lack of storage facilities and delayed payments which mean these problems were alike for farm size categories.

\section{References}

Acharya, S. S., and Agarwal, N.L. 2011.Agricultural marketing in India. Mohan Primalani for Oxford and IBH Publishing Company, New Delhi., p.312.

Bhrot, N.P. 1998. Genetical analysis of wild pomegranate for same growth ecological and quality characters. Ph.D Thesis, Dr Yashwant Singh Parmar University of Horticulture and Forestry,
Nauni, Solan (Himachal Pradesh), India.

Dogra, D.S. 2013. Economics of production and marketing of wild pomegranate in Himachal Pradesh. PhD Thesis. Dr Yashwant Singh Parmar University of Horticulture and Forestry, Nauni, Solan (Himachal Pradesh), India.

Kashyap, R., and Guleria, A. 2015. Socioeconomic marketing analysis of apple growers in Mandi District of Himachal. Journal of hill agriculture.6 (2): 202206.

Gupta, S.P. 2009. Statistical methods. $38^{\text {th }}$ revised edition. New Delhi: Sultan Chand and Sons.p.1468.

Jasdanwalla, Z.Y. 1966. Marketing efficiency in Indian agriculture. Allied Publishers Private Limited, Bombay.p.577.

Randev, A.K. 2005. Marketing of apple in Shimla district of Himachal Pradesh. Indian journal of agricultural marketing.19 (3): 12-19.

Sharma, S.D., and Sharma, V.K. 1990. Variation of chemical characters in some promising strains of wild pomegranate (Punica granatum L.). Euphytica.49: 131-133.

\section{How to cite this article:}

Devender Singh Dogra, Chandresh Guleria, Amit Guleria and Manoj Kumar Vaidya. 2017. Market Analysis and Problem Faced by the Wild Pomegranate Growers in Himachal Pradesh, India. Int.J.Curr.Microbiol.App.Sci. 6(7): 1551-1558.

doi: https://doi.org/10.20546/ijcmas.2017.607.185 